\title{
Análisis de la política pública de transparencia activa municipal en Chile durante 2012-2016
}

\author{
Javiera Kretschmer \\ Universidad del Desarrollo
}

\section{Resumen}

La transparencia tiene como objetivo el buen gobierno, permitiendo a los ciudadanos estar informados del quehacer gubernamental, la rendición de cuentas, estrechando la comunicación entre las autoridades políticas, funcionarios públicos y la ciudadanía en general. A partir de 2001, el Índice de Percepción de la Corrupción en Chile ha disminuido paulatinamente, siendo necesario mejorar la transparencia en gestión pública, dando a la Ley $\mathrm{N}^{\circ} 20.285$, de acceso a la información pública y transparencia. Si bien dicha ley se aplica a las municipalidades, un importante porcentaje de la ciudadanía las percibe como la institución pública más corrupta. Por ello, esta investigación analiza la información publicada por las municipalidades como consecuencia de las obligaciones establecidas por la Ley № 20.285, respecto del periodo 2012-2016, concluyendo que la política pública de transparencia activa municipal está condicionada por factores políticos, burocráticos, demográficos y socioeconómicos, siendo las más significativas la cantidad de periodos que lleva un alcalde como autoridad electa; el nivel de urbanismo y desarrollo, la edad promedio por comuna; la escolaridad promedio; y, el índice de pobreza comunal.

Palabras clave: Transparencia, municipalidades, corrupción. .

Analysis of the public policy of active municipal transparency in Chile during 2012-2016

\begin{abstract}
Transparency has as an aim good government, allowing citizens to be informed about the governmental actions, accountability and reducing communication breach between political authorities, government employees and citizens. From 2001, the Corruption Perception Index diminished gradually, being necessary to improve transparency in public management, which originated to the 20.285 Law, referred to access to the public information and transparency. Nonetheless this law is applied to municipalities, a significant percentage of citizens perceive them as the most corrupt public institution. Therefore, this investigation analyzes the information published by municipalities as a consequence of the obligations established by 20,285 Law, regarding the period 2012-2016, concluding that the public policy of active transparency of municipalities is conditioned by political, bureaucratic, demographic and socioeconomic factors, being the most significant the number of periods that a mayor has been elected; the level of urbanism and development of the commune, the average age per commune; average schooling; and the poverty rate of the commune.
\end{abstract}

Keywords: Transparency, municipalities, corruption..

\footnotetext{
*Dirección de correspondencia [Correspondence address]: Javiera Kretschmer, Universidad del Desarrollo

E-mail: javiera.kretschmer@gmail.com
} 


\section{Introducción}

La transparencia, así como el acceso a la información pública, es una práctica que tiene el objetivo de alcanzar un buen gobierno, permitiendo que los ciudadanos estén informados del quehacer gubernamental. Por otra parte, las señaladas prácticas permiten rendir cuentas y estrechar la comunicación entre las autoridades políticas, funcionarios públicos y la ciudadanía en general, posibilitando una mejora sustantiva en la calidad de vida y entorno de los habitantes de la comunidad política.

Un gobierno transparente no debe ser un lujo de países desarrollados ni menos el resultado del azar. Por el contrario, es una cuestión necesaria y fundamental que permite mejorar la gestión pública y escrutar los resultados de quienes detentan el poder y ejercen la función pública.

Por lo pronto, la falta de transparencia aleja a la ciudadanía de los gobiernos y deslegitima a las instituciones públicas. Una muestra de ello es lo mencionado por Fuenmayor, 2004), quien asevera que las malas prácticas de los gobiernos, en cuestiones asociadas a corrupción y desempeño institucional, ha producido una pérdida de la confianza de las personas hacia sus gobiernos, perdiendo el respeto a las instituciones.

Lo recién señalado se ha producido en Chile. En efecto, durante los últimos cinco años, la corrupción se ha vuelto una temática de pleno interés público y político, concentrando la atención de los medios de comunicación, así como de opinión pública. Los casos de financiamiento irregular en la política, malversación de caudales públicos y el tráfico de influencias han colmado de agenda pública, política e informativa.

Dichos actos han generado un aumento de la percepción de corrupción de la ciudadanía respecto de los gobernantes. Por ejemplo, la encuesta anual del Centro de Estudios Públicos (CEP), de mayo de 2017 , muestra que un $32 \%$ de los encuestados considera que el gobierno debería dedicar mayor esfuerzo a solucionar problemas de corrupción enraizados en Chile.

Ello se une a lo señalado en el Índice de Percepción de la Corrupción (2016), elaborado por Transparency International, en el cual Chile se ubica en la posición número 24 de un total de 180 países evaluados respecto de la corrupción. Si bien es el segundo país de América Latina mejor posicionado, superado sólo por Uruguay en el puesto número 21, se evidencia que el país ha desmejorado su posición en este índice, ya que en el informe anterior ocupaba el segundo puesto de la región, pero su lugar era el 21 del índice general.

A lo dicho se agrega que a partir 2001, después que se conoció públicamente el Caso MOP-Gate, el Índice de Percepción de la Corrupción en Chile fue disminuyendo paulatinamente, pasando de tener una puntuación de 7.5 en el 2000 a 6.9 en $2008^{1}$.

La situación anterior fue el génesis de la Ley $\mathrm{N}^{\circ} 20.285$, sobre acceso a la información pública y transparencia, norma que, con el paso del tiempo, se ha convertido en uno de los hitos fundamentales en lo que se refiere al combate a la corrupción y falta de probidad en Chile. Esta ley se ha transformado en la llave que valida la transparencia de los organismos públicos y el acceso a la información pública en manos de los gobernantes y autoridades públicas con y para la ciudadanía.

Al revisar el contenido de la Ley $\mathrm{N}^{\circ} 20.285$ se tiene que su artículo $2^{\circ}$ regula los órganos del Estado a los cuales aplica, dentro de los cuales incluye a los ministerios, intendencias, gobernaciones, gobiernos regionales, municipalidades, fuerzas armadas, de orden y seguridad pública, así como los órganos y servicios públicos creados para el cumplimiento de la función administrativa.

Como consecuencia de lo señalado en la frase final del inciso $1^{\circ}$ del artículo $2^{\circ}$ citado, la ley examinada es de aplicación general para los órganos del Estado y servicios públicos creados para el cumplimiento de la función administrativa, considerándolos considera a todos por igual, sin importar su tamaño, cantidad de funcionarios, presupuesto anual asignado, marco normativo, entre otros aspectos, sintetizando que todas las instituciones dentro de esta categoría deben regirse por la misma normativa.

Dentro del contexto señalado, se tiene que los órganos del Estado se organizan funcional y territorialmente, existiendo administraciones territoriales que poseen competencia sobre el país, las regiones, las provincias y las comunas, respectivamente.

De forma particular, el ordenamiento jurídico nacional entrega la administración comunal a las municipalidades, las que son la división territorial y administrativa más pequeña del país, pretendiendo ser la institución política y administrativa más cercana a la ciudadanía, siendo su "[...] finalidad es satisfacer las necesidades de la comunidad local y asegurar su participación en el progreso económico, social y cultural de las respectivas comunas" (Ley № $18.695,2006)$.

Sin embargo, el hecho que la ley mandate que las

1 La puntuación se mide de 0 a 10, considerando 0 como un país con alta corrupción en el servicio público y con 10 puntos un país limpio sin problemas de corrupción. 
municipalidades tengan el objetivo de satisfacer las necesidades públicas de las comunidades locales no supone, de forma necesaria, la existencia de un mayor contacto y participación política respecto de los ciudadanos que habitan dichos territorios. En efecto, al revisar los resultados de participación de la ciudadanía en las elecciones municipales, se obtiene que, para el año 2016, dicho solo un $34 \%$ de los votantes habilitados para sufragar participó, erigiendo a dichas elecciones en la instancia en que la menor cantidad de ciudadanos ha asistido a votar desde 1990. Asimismo, y en correlación con los espacios de participación ciudadana creados mediante la Ley $\mathrm{N}^{\circ} 20.500$, solo un $44 \%$ de los municipios de Chile cuenta con un Consejo Comunal de la Sociedad Civil (CCSC).

En correlato con lo señalado, se puede apreciar que, desde 2006 a la actualidad, los resultados de la encuesta CEP arrojan que la ciudadanía percibe que la institución donde es posible hallar mayor corrupción es en las municipalidades. La situación antes mencionada se grafica en que el 2006 un $33 \%$ de los encuestados consideraba que la institución más corrupta de las nombradas eran las municipalidades. Ese porcentaje, para el año 2017, subió dramáticamente a $45 \%$.

A propósito de esta información es preciso preguntarse: ¿Cómo se gestiona la transparencia en los municipios de Chile? ¿Están logrando los objetivos las políticas públicas de transparencia que han implementado los organismos y leyes? ¿Cuán efectiva en cumplimiento es la Ley № 20.285? ¿Qué relación existe entre la transparencia municipal y factores endógenos? ¿Son éstos, un obstáculo para el funcionamiento de la política pública de transparencia activa municipal?

Teniendo presente las preguntas antes formuladas, esta investigación tiene como objetivo general evaluar el cumplimiento de las disposiciones de transparencia activa contenidas en artículo $7^{\underline{0}}$ de la Ley № 20.285 para las municipalidades, respecto del periodo 2012-2016, en pos de comprender cuáles son los factores que se correlacionan en su cumplimiento.

Asimismo, los objetivos específicos de esta investigación son:

- Analizar la información existente y publicada por las municipalidades respecto de las disposiciones contenidas en el artículo $7^{\underline{0}}$ de Ley $\mathrm{N}^{\underline{0}}$ 20.285, respecto del periodo 2012-2016.

- Construir un índice que mida el nivel de transparencia activa de las municipalidades, según las dispoiciones contenidas en el artículo $7^{\underline{0}} \mathrm{de}$ Ley № 20.285, respecto del periodo 2012-2016.
- Detallar y explicar los factores que tienen correlación en el índice de transparencia activa de las municipalidades durante el periodo 20122016.

De esa forma, surge la hipótesis general de este trabajo, entendida como la política pública de transparencia activa municipal está condicionada por factores políticos, burocráticos, demográficos y socioeconómicos de las comunas de Chile.

\section{La transparencia: un nuevo parámetro de acción para los órganos del Estado.}

La palabra transparencia es utilizada frecuentemente, convirtiéndose en pieza fundamental de los planes de gobierno de entes públicos y privados, situación por la cual, en lo referente a la gobernanza y diseño institucional, puede ser definida de diversas maneras.

Por lo pronto, Transparency International ha especificada que este concepto es aquella acción consistente en translucir las reglas, planes, procesos y acciones. Es saber por qué, cómo, qué y cuándo. Desde la perspectiva anotada, la transparencia asegura que los funcionarios públicos, los administradores, los miembros del consejo y los empresarios actúen de manera visible y comprensible, e informen, al mismo tiempo, respecto sus actividades. A la vez, transparencia significa que el público en general puede tenerlos en cuenta, siendo la manera más segura de protegerse contra la corrupción y ayuda a aumentar la confianza en las personas e instituciones de las que depende el futuro (Transparency International, 2010).

Asimismo, la Organización para la Cooperación Económica y el Desarrollo (OECD) definió hace algunos años el mencionado concepto como "el proceso por el cual la información de las condiciones existentes permite ser anexada para la toma de decisiones y acciones, de manera visible y entendible".

Esa conceptualización ha sido recogida en el ámbito académico, ya que no se circunscribe solamente a una aplicación de ella por los gobiernos públicos y privados, sino que hace hincapié respecto de la utilización de la información, mediante el reconocimiento del derecho a acceso a la información, el cual debe ser claro y comprensible (De León, 2008). Aquello se relaciona directamente con el acceso a la información pública, puesto que el entregar información a un ciudadano que la solicite, se erige en una acción transparente de rendición de cuentas (Álvarez, 2010).

En esa orientación, el Consejo para la Transpa- 
rencia (CPLT) define el acceso a la información pública como "el derecho que permite a cualquier persona tener conocimiento de la información que se encuentra en cualquier entidad estatal. La Ley de Transparencia lo desarrolla en dos dimensiones: transparencia activa y transparencia pasiva" (Consejo Para la Transparencia, 2011).

El citado concepto se encuentra estrictamente relacionado con el contenido de la Ley $\mathrm{N}^{\circ} 20.285$, ya que aquel fue la principal herramienta conceptual para la redacción de la misma, puesto que el derecho de acceso a la información, así como el principio de probidad, había recibido consagración constitucional como consecuencia de la reforma introducida en el año 2005 (Ley № 20.285, 2008).

La referida reforma, producto de una recomendación de la Comisión Nacional de la Ética Pública, incorporó un nuevo artículo $8^{\circ}$ a la Constitución Política, el cual, en su inciso $2^{\circ}$, dispone que " $[\mathrm{s}]$ on públicos los actos y resoluciones de los órganos del Estado, así como sus fundamentos y los procedimientos que utilicen. Sin embargo, sólo una ley de quórum calificado podrá establecer la reserva o secreto de aquéllos o de éstos, cuando la publicidad afectare el debido cumplimiento de las funciones de dichos órganos, los derechos de las personas, la seguridad de la Nación o el interés nacional".

Como se puede apreciar, sin perjuicio que la Constitución Política estableció el derecho de acceso a la información pública, no existía en la época un mecanismo apropiado que garantizara a la sociedad conocer, comprender y pedir cuentas respecto de las decisiones, así como de sus fundamentos e implementación. Menos existían mecanismos que permitieran acceder a los antecedentes que fundamentan la creación de las políticas al interior de las instituciones públicas.

Lo dicho da cuenta de la necesidad de avanzar en esta materia, la que se fundamenta, entre otras consideraciones, en establecer mecanismos que propendan a un mayor control, por parte de la ciudadanía, de los actos de la Administración, con el objeto que el ejercicio del poder no sea arbitrario.

En consecuencia, la transparencia encierra una serie de bienes jurídicos de alcance individual y colectivo. Individualmente, la publicidad es presupuesto del ejercicio de ciertos derechos. Colectivamente, permite un real ejercicio democrático, un mayor control del poder en beneficio del bien común y, finalmente, es un presupuesto de la vigencia de la responsabilidad de los gobernantes. Todo lo anterior, en el entendido que los órganos públicos mantienen cierto nivel de información no a efectos de resguardar su propio interés sino para el cum- plimiento de una función tendiente al bien común (Avilés, 2009).

Como se aprecia, el establecimiento de la Ley $\mathrm{N}^{\circ}$ 20.285 es un mecanismo que ha permitido garantizar la publicidad de los actos de los órganos del Estado. En tal sentido, su artículo $4^{\circ}$ pone en manifiesto que el principio de transparencia de la función pública "consiste en respetar y cautelar la publicidad de los actos, resoluciones, procedimientos y documentos de la Administración [...] a través de los medios y procedimientos que al efecto establezca la Ley".

Para el cumplimiento del cometido antes señalado, la Ley $\mathrm{N}^{\circ} 20.285$ regula dos manifestaciones distintas de la transparencia en la gestión pública. Por un lado, el Título III regula la transparencia activa, la cual es desarrollada por los órganos del Estado de forma obligatoria, sin que medie la necesidad de una solicitud o petición de información por parte de los ciudadanos. En tal sentido, cada institución debe publicar una serie de antecedentes en su sitio web, según lo establecido en el artículo $7^{\circ}$ de la Ley № 20.285 .

Por otra parte, el Título IV de la citada ley consagra el derecho de acceso a la información de los órganos de la Administración del Estado, también llamada transparencia pasiva, estableciendo, en sus artículos 10 al 25, procedimientos de solicitud de información a los órganos públicos, los que tienen por objeto que la ciudadanía pueda acceder a la información específica y que no se encuentre publicada en las páginas web del organismo público al cual es solicitada.

En orden a cautelar que la información sea publicada por parte de los servicios públicos, así como el derecho de acceso a la información establecido en favor de la ciudadanía, la Ley N²0.285 creó el CPLT, corporación autónoma de derecho público y patrimonio propio cuya labor es fiscalizar y velar por el cumplimiento de dicha norma, cooperando con las demás instituciones públicas en la generación e institucionaliza de una cultura de transparencia en Chile. Asimismo, el CPLT es la institución pública a la cual la ciudadanía puede acudir en el evento que se les deniegue, por parte de los órganos de la administración del Estado, el acceso a información pública o no cumpla con el deber de transparencia activa, establecido en el artículo $7^{\circ}$ de la ley.

Desde su creación, el CPLT se ha erigido en una institución pública cada vez más relevante. A modo ejemplar, en 2013 dicho organismo recibió más de 81 mil amparos de información pública, aumentando en más de 50 mil solicitudes en comparación a 
los primeros años de funcionamiento de dicho Consejo (Consejo Para la Transparencia, 2014) ${ }^{2}$. Este hecho puede ser explicado a raíz de una serie de hechos relacionados con eventos de corrupción dentro del Gobierno y ciertos servicios públicos. De esa forma, se puede colegir que el conocimiento público de casos de contravención al principio de probidad y de corrupción coinciden, en alguna medida, con el aumento de solicitudes amparo de información al CPLT.

Entre los mencionados casos de corrupción y falta a la probidad se tiene, en primer lugar, el caso "MOP-GATE", el que generó gran impacto en la opinión pública, afectando la confianza de la ciudadanía en los organismos públicos (Delgado y Radio Bio Bio, 2015). Este caso fue protagonizado por funcionarios del Ministerio de Obras Públicas (MOP) y la empresa Gestión Ambiental y Territorial Sociedad Anónima (GATE S.A.), consistiendo en el pago, por parte del MOP, de sobresueldos a funcionarios por trabajos que nunca se hicieron. Al mismo tiempo, GATE S.A. recibió pagos injustificados por supuestas autopistas concesionadas, hechos que dieron lugar a la constatación de un fraude al fisco que ascendió a un total de $\$ 1.253$ millones de pesos.

Otro ejemplo de escándalos de corrupción se tuvo durante el año 2014 como resultado de una denuncia por delitos tributarios realizada en contra de la empresa Penta S.A. por uso irregular de boletas de honorarios y facturas ideológicamente falsas para disminuir el pago de impuestos. La acción del mencionado grupo económico permitió financiar una serie de campañas políticas de forma irregular, pues, según Servicio Impuestos Internos (SII), la evasión de impuestos entre 2008-2010 fue cercana a los 2 mil millones de pesos, monto que casi se dobló en el año 2013 como resultado del financiamiento irregular de campañas políticas de aspirantes al Congreso Nacional (Monckeberg, 2015).

A nivel local, también es posible verificar casos de corrupción. En efecto, durante la presente década se han conocido un par de casos relacionados con corrupción a nivel municipal. En ese orden de ideas, en 2013 se condenó a las autoridades de la comuna de Nogales por haber realizado una estafa por más de 1.300 millones de pesos como consecuencia de malos manejos de efectivos, favores políticos, sobresueldos, entre otros hechos. Más de las acciones realizadas con ese dinero carece de justificación y respaldo legal (ChileTransparente).

\footnotetext{
${ }^{2}$ Dentro de los diez organismos con mayor cantidad de solicitudes de transparencia pasiva se pueden contar a seis municipalidades, a saber, Santiago, Quilicura, Peñalolén, Maipú, Recoleta, Concepción y Arica. Los otros organismos más requeridos son la Superintendencia de Electricidad y Combustibles, la Subsecretaría de Educación y Gendarmería de Chile.
}

En 2015 el ex-diputado Orlando Vargas y el exalcalde de Arica Waldo Sankán fueron formalizados por tráfico de influencias y por presunto fraude al fisco, por haberse entregado beneficios económicos al ex edil y diversos integrantes del Concejo Municipal de esa comuna, con el objeto que renovasen la licitación de las empresas encargadas de recoger los desechos domiciliarios sólidos.

Es posible concluir de lo presentado, que el funcionamiento de la Ley de Transparencia ha desencadenado un proceso que parece irreversible. En efecto, la aplicación de las potestades del CPLT ha implicado que los municipios deban, necesariamente, poner en marcha nuevos mecanismos que han aumentado la rendición de cuentas de esas entidades.

Lo anterior es producto de la aplicación de lo establecido en el artículo 33 de la ley, la cual mandata al Consejo a capacitar, dictar instrucciones y a fiscalizar el cumplimiento de la ley. Ello es, sin duda, una cuestión de alto impacto que ha venido no sólo a modificar las estructuras administrativas de algunos municipios, sino que a la vez, ha implicado una mayor difusión de la ley y mayores estándares de disponibilización de información hacia la ciudadanía, modernizando, en consecuencia, la función pública desplegada por las municipalidades.

La situación mencionada no es producto solamente de la entrada en vigencia de la Ley de Transparencia, sino que es un proceso que se ha venido generando durante los últimos tres gobiernos, los cuales han promovido iniciativas de modernización del Estado, siendo su principal objetivo revertir, prevenir y controlar la generación de este tipo de situaciones al interior de los organismos públicos.

En ese contexto, durante el Gobierno del Presidente Ricardo Lagos (2003) tuvo lugar un acuerdo político-legislativo para la modernización del Estado, Transparencia y promoción del crecimiento, cuyo Punto II especifica los ejes de la agenda de Transparencia, entre los cuales se cuentan aspectos relativos al financiamiento de la política, la labor parlamentaria y la institucionalidad y la probidad. Ninguno de los aspectos mencionados fue concretado.

Sin perjuicio de lo dicho, es menester señalar que la reforma introducida a la Constitución Política en 2005, mediante la Ley № 20.050, elevó a rango constitucional el principio de transparencia, el cual había sido introducido como un principio rector de las actuaciones de los órganos de la administración del Estado, en 1999, mediante la Ley № 19.653.

Posteriormente, en 2007, se elaboró un documento titulado "Informe sobre medidas para fortalecer la probidad y eficiencia de la gestión pública en- 
cargada por la S.E Presidenta de la República Michelle Bachelet", cuyo objetivo era proponer orientaciones fundamentales para la reforma del sector público. Uno de los aspectos fundamentales fue el relativo a las medidas de transparencia activa y pasiva (Capítulo II), las cuales, en gran medida, se cumplieron gracias a la promulgación de la Ley $\mathrm{N}^{\circ}$ 20.285 .

Otro aspecto destacable fue el relacionado con medidas que buscaban favorecer la probidad y transparencia (Capítulo VI), proponiéndose el mejoramiento de las reglas que establecen prohibiciones a las personas que cometan actos de corrupción al interior de los órganos públicos, mediante un proyecto de ley (Boletín № 9.957-07), el cual, luego de ingresado a la Cámara de Diputados, no ha tenido avances.

En fin, y como consecuencia de los casos de corrupción asociados al financiamiento irregular de las campañas políticas de 2013, durante el año 2015 se creó el Consejo Asesor Presidencial en contra de los conflictos de interés, el tráfico de influencias y la corrupción (Consejo Asesor Presidencial contra los Conflictos de Interés, 2015), cuyo principal propósito era "proponer un nuevo marco normativo, que permita el cumplimiento efectivo de los principios éticos, de integridad y transparencia, en sus aspectos legales y administrativos para logar el eficaz control del tráfico de influencias, prevención de la corrupción y de los conflictos de interés en los ámbitos de los negocios, la política y el servicio público, así como en la relación entre éstos".

De los recién mencionados documentos relativos a la modernización del Estado, sólo el último ha sido puesto en marcha, en orden a priorizar la probidad y transparencia a nivel municipal, dada la importancia que dichos entes públicos poseen respecto de la vinculación del poder político con la ciudadanía. En efecto, en orden a obtener el antedicho cometido, fueron presentadas una serie de propuestas tendientes a mejorar la gestión y resultados favorables en materia de políticas de control y fiscalización, así como establecer la obligatoriedad de auditorías por parte de la Contraloría General, mejorar los mecanismos de regulación de transferencias municipales y mejorar los límites respecto del poder político de las autoridades, estableciendo un máximo de periodos de función de los alcaldes (Consejo Asesor Presidencial contra los Conflictos de Interés, 2015).

Los hechos antes detallados pueden ser comprendidos desde una perspectiva teórica, ya sea se que tomen como un factor de fallas de mercado, desarrollo intrínseco de la democraciay rendición de cuentas.
Desde una aproximación neoinstitucionalista, se tiene que existen fallas intrínsecas del mercado en aquellos casos en que no existan mercados completos, situación por la cual la información es asimétrica e imperfecta. Aquello tiene como consecuencia que las decisiones que se tomen no posean una calidad óptima, pudiéndose generar diferencias, en el mercado mismo, por la obtención de información. Por lo mismo, "[m]uchas veces los Gobiernos no disponen de la información necesaria para tomar decisiones. [...] Sin embargo, la información limitada del Estado puede impedirle distinguir entre los que están verdaderamente incapacitados y los que simulan" (Stiglitz, 2003: 17). En consecuencia, la problemática reseñada justifica y hace necesario el desarrollo de normas jurídicas, por parte del Gobierno, que pretendan corregir las mencionadas fallas.

Como se aprecia, el criterio económico usado para decidir respecto de la intervención del Estado es el referente a las fallas de mercado, las cuales pueden ser entendidas como aquellas situaciones en que el mercado no funciona de manera adecuada y genera perjuicios para la sociedad.

Stiglitz establece que, habitualmente, la teoría económica concibe cuatro tipos de fallas:

- Competencia imperfecta: Tiene lugar cuando un agente posee alguna ventaja incontrastable, como sucede en los monopolios.

- Externalidades: Entendidas como el surgimiento de un beneficio o daño para un agente o muchos de ellos.

- Fallas a largo plazo: Se generan cuando la falta de información ocasiona un perjuicio presente o futuro para una de las partes (agenteprincipal).

Lo recién señalado puede relacionarse con la denominada teoría de la agencia, la cual tiene por objetivo mostrar la relaciòn entre actores que se sitúan en dos denominaciones; el principal (el que delega autoridad, que en este caso son los ciudadanos) y el agente (al que se le delega la autoridad) a partir del juego de intereses que se conjuga en las asimetrías de la información que dificultan el monitoreo del primero sobre el segundo, con el fin de cubrir las necesidades o, de igual manera, los intereses de los principales (Arjona, 2005).

Interpolando lo anterior a la transparencia municipal, se podría visualizar que aplicando el enfoque principal-agente se comprendería la importancia de una definición clara de los roles. En este caso en particular, el rol del principal lo debiese los ciudadanos 
y el CPLT como entes fiscalizadores en la coordinación de la transparencia de servicios dependientes (municipios) (Silva y Meléndez, 2011).

Para una mayor comprensión, se tiene que para efectos de esta investigación el principal es el CPLT; el agente son las municipalidades; y, la delegación de actuar al cual se ajusta esta relación es la Ley № 20.285. En ésta se especifican cada una de las obligaciones de publicar información de los órganos comunales, las que, de no ser cumplidas, puede implicar sanciones por parte del CPLT (artículos 31 y 32 de la Ley $\mathrm{N}^{\circ} 20.285$ ).

Particularmente, se asume que el principal (CPLT) puede observar los niveles de producto que resultan las acciones del agente, "asumiremos que hay $n$ niveles de producto $\mathrm{x}=1,2, \ldots \mathrm{n}$, que recibe el principal y unas acciones a, b, c que puede tomar el agente. También, cada acción tiene un determinado costo para el agente" (Silva y Meléndez, 2011: 4), lo que conlleva a interpretar que las municipalidades deben asignar cierto costo a mantener reglas de transparencia, entre ellas, tener a alguien encargado del servicio de transparencia y publicaciones del gobierno local, así como asumir un costo monetario en caso de no cumplir con los requisitos de transparencia activa, potestad del CPLT según el artículo 42 de la ley.

De esta forma, se presenta entonces un caso de información asimétrica, ya que el agente sabe que acción tomar en cuanto a la publicación de información asociada a transparencia activa y el principal, no. Por ello, se plantea entonces el problema respecto a qué debe hacer el principal para inducir al agente a hacer lo correcto, lo que, para esta investigación, se establece en las responsabilidades comprendidas por ley y las consecuencias a las que se ajusta, en caso que el agente (municipio) no cumpla con aquello.

Asumiendo que la información es asimétrica, es decir que el agente sabe más que el principal respecto del oficio que desempeña, se tiene que es posible verificar la existencia de lo que en economía se denomina como un problema de información oculta o selección adversa (Gorbaneff, 2003). Lo dicho tiene lógica en el espacio público, ya que si bien el CPLT es quien fiscaliza, son los municipios los únicos entes que tienen acceso a la información requerida para el cumplimiento de cada una de las disposiciones de la Ley $\mathrm{N}^{\circ} 20.285$, como sucede con los presupuestos asignados, los subsidios otorgados, las adjudicaciones de compras públicas, entre otros aspectos.

Desde la perspectiva del Accountability, el cual se refiere a la necesidad de controlar el poder público por medio de mecanismos que obligan a los fun- cionarios a informar y justificar sus acciones y que pueden ser objeto de sanción (Schedler et al., 1999). Considerando éste como considerado como una mera práctica democrática cuyo reconocimiento aspira a lograr resolver las siguientes incógnitas del debate público, entre ellas, quién rinde cuentas, quién las recibe, cómo se rinden de acuerdo a lo estipulado por la ley y cuál es el objetivo de la rendición de cuentas.

Interpolando lo anterior a la investigación, no es difícil identificar las respuestas a las preguntas, pues se entiende que quien rinde cuentas en este caso son los municipios, quién las recibe son los vecinos de las comunas, el cómo realizarlo, se estipula según el artículo $7^{0}$ de la Ley $\mathrm{N}^{\mathrm{O}} 20.285$ en referencia a la transparencia activa municipal, y finalmente el objetivo de esta rendición de cuentas es acortar las brechas de información que existe entre el principal y el agente. Por otro lado, el accountability horizontal, Un segundo tipo de el cual hace referencia a la idea de que sea el Estado el que se controle a sí mismo. En efecto, el accountability horizontal parte de la premisa de que las propias instituciones del Estado deben encargarse de vigilarse entre sí, cuestión que se vincula directamente con el rol de principal agente entre los Municipios y el CPLT.

Finalmente la teoría de la agencia y la de Accountability se toman como una técnica de perfeccionamiento del poder, donde el objetivo de las instituciones en conjunto con sus integrantes es ayudar a la ciudadanía a reducir la asimetría de información.

La aproximación teórica de la presente investigación se vinculará con el trabajo cuantitativo y práctico, el cual fue realizado por medio de una metodología de regresiones y medición del cumplimiento de transparencia activa de los municipios de Chile. En los siguientes dos apartados se puede revisar la metodología y los resultados del comportamiento transparente que sostienen o marginan las municipalidades del país.

\section{Metodología}

El enfoque de esta investigación es cuantitativo y explicativo, ya que pretende explicar si la política pública de transparencia municipal, englobada en el cumplimiento de transparencia activa de la Ley № 20.285, está correlacionada a factores políticos, burocráticos, demográficos y socioeconómicos de las comunas chilenas. Asimismo, esta investigación se caracteriza por ser un estudio comparado por panel, ya que la temporalidad de investigación comprende los años 2013 al 2016, ambos inclusive. 
En orden a medir el grado de cumplimiento de transparencia activa municipal, se utilizó una variable binaria, es decir, si el portal web municipal tenía publicada la disposición legal por cada año, se cuantificaba con un 1, caso contrario, con un 0 . La información analizada fue obtenida desde los sitios web de las municipalidades del país. Es menester hacer presente que hubo casos cuyos sitios web se encontraban desactualizados, por lo cual hubo municipios que no fueron contemplados en la base de datos general de la presente investigación ${ }^{3}$.

Las disposiciones relacionadas con la transparencia activa municipal, contempladas en el artículo $7^{0}$ de la Ley № 20.285 , son las siguientes:

- La estructura orgánica, disposición simétrica y ordenada de los órganos y/o departamentos que integran la institución de una manera jerarquizada.

- Las facultades, funciones y atribuciones, la cual se refiere a las responsabilidades de la organización interna del organismo público.

- El marco normativo que le sea aplicable, haciendo referencia al conjunto de leyes, normas, decretos, reglamentos de carácter obligatorio que rija la institución.

- La planta de personal, personal a contrata y honorarios y sus respectivas remuneraciones, donde los organismos públicos deben informar sobre el nombre completo, y cantidad de personas que trabajan en la institución como personal de planta, a contrata u honorarios, en base al sueldo mensual que reciban por sus respectivos servicios al órgano.

- Las contrataciones para el sumisito de bienes muebles, para la prestación de servicios, para la ejecución de acciones de apoyo y para la ejecución de obras, y las contrataciones de estudios, asesorías y consultorías relacionadas con proyectos de inversión, con indicación de los contratistas e identificación de los socios y accionistas principales de las sociedades o emprestas prestadoras, en su caso. La cual se entiende como los alquileres que realizan los órganos públicos de bienes muebles, servicios y realización de acciones de apoyo para el cumplimiento de obras y contrataciones. A la vez identificación de los contratistas, accionistas y principales sociedades o empresas prestadoras de servicio.

\footnotetext{
${ }^{3}$ Los municipios cuyos portales web de transparencia estaban desactualizados y no había conexión fueron: Calama, Camarones, Canela, Catemu, Cerrillos, Chonchi, Coyhaique, Colina, Empedrado, Freirina, Lolol, Lonquimay, Maule, Ollague, Renaico, Sagrada Familia, Talca y Toltén.
}

- La transferencia de fondos públicos que se efectúen incluyendo todo aporte económico entregado a personas jurídicas o naturales, directamente o mediante procedimientos concursales, sin que éstas o aquellas realicen una contraprestación recíproca en bienes o servicios. Ésta hace referencia a las transferencias de dineros públicos y/o subvenciones entregadas por la institución pública a personas jurídicas o naturales por medio de concursos públicos del organismo.

- Los actos y resoluciones que tengan efectos sobre terceros. Éstos son todos aquellos actos o toma de decisiones que tengan efectos en otras instituciones y personas independientes a la institución.

- Los trámites y requisitos que debe cumplir el interesado para tener acceso a los servicios que preste el órgano. Se entiende como las condiciones y trámites con los que debe cumplir una persona natural o jurídica para acceder a los servicios y ayudas que entrega la institución respectiva.

- El diseño, montos asignados y criterios de acceso a los programas de subsidios y otros beneficios que entregue el órgano. Hace referencia a todos los subsidios y beneficios que entrega el municipio a sus vecinos, deben encontrarse definidos según su diseño, monto a entregar y criterios de postulación y asignación.

- Los mecanismos de participación ciudadana. Los organismos públicos deben publicar los mecanismos de participación ciudadana, los cuales son todas aquellas instancias donde se convoca a la participación de los vecinos y/o interesados en el tema.

- La información sobre el presupuesto asignado, así como los informes sobre su ejecución, en los términos previstos en la respectiva Ley de Presupuesto de cada año. Por esta se comprende Toda aquella información relacionada con el presupuesto institucional, tanto el presupuesto aprobado por cada año, los balances de ingresos y egresos y los informes de ejecución o modificación del presupuesto.

- Los resultados de las auditorías al ejercicio presupuestario del respectivo órgano. Entendiendo esto como los resultados e informes finales de las auditorías realizadas por la Contraloría General de la República sobre la ejecución presupuestaria de la institución.

- Todas las entidades en que tenga participación, representación e intervención el organismo público. Se refiere a todos aquellos organis- 
mos y entidades externas en el cual el municipio tenga representación y toma de decisiones.

La información respecto las variables políticas, burocráticas, demográficas y socioeconómicas de los municipios fueron extraídas desde fuentes secundarias. Para efectos metodológicos, algunas de esas variables son binarias y otras, numéricas continuas.

En primer lugar, las variables políticas utilizadas para la elaboración de esta investigación son las siguientes:

- Padrón electoral: Es el registro donde consta el conjunto de personas naturales a las que la legislación reconoce el derecho de sufragio. En éste se reconoce la cantidad de personas habilitadas para votar por cada comuna. Dicha información se extrajo del Servicio Electoral Chileno (SERVEL) para las elecciones municipales del año 2013. Esta variable es de carácter numérico continua.

- Porcentaje de participación electoral por comuna: Relación existente entre los ciudadanos habilitados para votar, según el padrón electoral, y aquellos que votaron. Esta variable es de carácter numérico, cuyo rango va entre 0 y 1 (porcentaje).

Según la encuesta de Gestión Municipal del 2016 del Centro de Políticas Públicas UC, establece que los datos aportados muestran que la gran mayoría de los chilenos cree relevante que se le considere su opinión en la gestión municipal. Sin embargo, alrededor de la mitad de las personas plantean que tienen interés en participar, con el objetivo de mejorar la gestión, pero a través de canales diferentes a los mecanismos tradicionales utilizados por los municipios.

- Partido político del alcalde: "cualquier grupo político identificado por una etiqueta oficial que presenta a las elecciones y puede sacar en elecciones (libres o no) candidatos a cargos públicos" (Sartori, 1980). Los partidos políticos que respaldaron a los alcaldes electos del espectro chileno que se pueden encontrar categorizados en esta variable son, desde lo más izquierda a lo más de derecha: Partido Comunista de Chile (PCCH), Partido Socialista (PS), Partido por la Democracia (PPD), Partido Radical de Chile (PRSD), Democracia Cristiana (PDC), Partido Regionalista Independiente (PRI), Renovación Nacional (RN), y Unión Demócrata Independiente (UDI).
Se generaron tres variables binarias, por un lado, considerando con valor 1 a todos los partidos de la coalición Nueva Mayoría, que agrupa todos los partidos de izquierda (PCCH, PS, MÁS, PPD, PRSD, PDC más los independientes con apoyo del conglomerado (ILE); y con valor 0 todos los alcaldes respaldados por partidos de la coalición de Alianza e Independientes que integra a los partidos de la centroderecha chilena (PRI, RN, UDI).

La segunda variable binaria le otorga el valor 1 a todos los alcaldes cuyo partido de respaldo haya sido de la coalición de Alianza (PRI-RN-UDI) y 0 si es que el partido es de izquierda o independientes.

La tercera variable se construyó otorgándole el valor 1 a los alcaldes independientes o respaldados por las listas ILA, ILC, ILF, ILB, ILH, PRO, y de no ser ningún de éstos se le consideró el valor 0 .

El índice Transparencia de Partidos Políticos Chilenos de Chile Transparente (2017), el $63 \%$ de los partidos políticos chilenos reprobó el índice que mide estructura de los procedimientos internos normativa, autoridades, representantes; ideología y posición programática -principios; financiamiento ingresos, egresos, balance anual; y contratos o convenios de bienes y servicios (Chile Transparente, 2017). En una escala de 1 a 7 (donde 7 es el que cumple con todas las disposiciones), los resultados arrojaron que el partido político más transparente en Chile es Renovación Nacional (RN) con nota 6,9; quien le sigue es el Partido Socialista (PS), después el Partido Progresista (PRO) con un 6,5 luego Revolución Democrática (RD) y luego el Partido Demócrata Cristiano (PDC) con nota 5,4.

Esta información demuestra que hay tres partidos que llevan años en el espectro político partidista chileno los cuales publican todo aquello que el índice de estudio busca. Pero a la vez se integra al top five dos partidos políticos nuevos, los cuales marcan un precedente en el formato de hacer política (Precht, 2017).

- Número de concejales por comuna: Las municipalidades estarán constituidas por el alcalde y el concejo (artículo 72 inciso $2^{\circ}$ de la Ley $\mathrm{N}^{\circ}$ 18.695). Cada concejo estará compuesto por:

- Seis concejales en las comunas o agrupaciones de comunas de hasta setenta mil electores;

- ocho concejales en las comunas o agrupaciones de comunas de más de setenta mil y hasta ciento cincuenta mil electores,

- diez concejales en las comunas o agrupaciones de comunas de más de ciento cincuenta mil electores. 
El número de concejales por elegir en cada comuna o agrupación de comunas, en función de sus electores, será determinado mediante Resolución del SERVEL (artículo 72 inciso $3^{\circ}$ de la Ley $N^{\circ} 18.695$ ).

La información se obtuvo desde los sitios web de cada una de las municipalidades analizadas. Se crearon tres variables de carácter binario. La primera toma valor 1 si es que la comuna tiene 6 concejales, en caso contrario se le otorga un 0. La segunda variable toma valor 1 cuando la municipalidad cuenta con 8 concejales electos y valor 0 en caso contrario y la tercera variable toma valor 1 cuando la comuna tiene 10 concejales y valor 0 en el caso que tenga valor distinto a 10 .

El grado grado de competencia política es un factor que aparece como determinante positivo del nivel de transparencia para los grandes municipios españoles, por ejemplo, (Cárcaba García y García García, 2010). A mayor número de opciones disponibles para que los ciudadanos elijan a sus representantes mayor el incentivo que deberían tener las corporaciones para divulgar información y someter su gestión al control de la ciudadanía.

- Cantidad de periodos en ejercicio por alcalde: El alcalde será elegido por sufragio universal, siendo su mandato de cuatro años, pudiendo ser reelegido (artículo 57 de la Ley № 18.695). Esta variable se entiende como la cantidad de periodos que lleva desempeñando el cargo. Se consideró dentro de los periodos ejercidos por el alcalde, el comprendido entre 2012-2016. Los satos se obtuvieron del sitio web del SERVEL. Esta variable es de carácter numérico continuo.

- Incumbencia del alcalde: Entendido como la acción de haber sido reelegido como alcalde de la comuna. Se trata de una variable binaria si el alcalde fue reelecto para el periodo 2012- 2016 y valor 0 si el edil fue elegido por primera vez como principal autoridad de la comuna.

- Sexo del alcalde: Representa si el edil del municipio electo para el periodo 2013 era hombre o mujer. Es una variable de carácter binario. $\mathrm{Si}$ alcalde es hombre toma valor 1 y en caso contrario toma valor 0 .

Seguidamente, como variables burocráticas de las comunas, se utilizaron las siguientes:

- Puntaje de fiscalización CPLT: La fiscalización tuvo por finalidad comprobar el cumplimiento de lo establecido en el Título III de la Ley $\mathrm{N}^{\circ}$ 20.285; en el artículo 51 del Reglamento de la
Ley $\mathrm{N}^{\circ} 20.285$; y en las Instrucciones Generales $\mathrm{N}^{\circ} 4,7$ y 9 del Consejo para la Transparencia (Consejo Para la Transparencia, 2014). Este estudio mide el nivel de cumplimiento de transparencia activa de los municipios de Chile. La información se obtuvo para el año 2013, 2014, 2015 y 2016 desde la sección "Estudios" del sitio web del CPLT. Esta variable es de carácter numérica continua, cuyo rango va de 0 a 1 (porcentaje).

El estudio de fiscalización de modalidad en línea del CPLT (2014), los resultados arrojaron que de las más de 300 solicitudes enviadas, solo el $69 \%$ fueron ingresadas como solicitud. De éstas solicitudes solo el 72,3\% obtuvieron respuesta dentro del plazo legal. Por lo que se proyecta que existe un nivel de cumplimiento regular.

Así mismo se manifiesta que solamente 26 de las municipalidades del país obtuvieron un $100 \%$ de cumplimiento, lo que equivale tan solo a un 7,5\% de todos los municipios de Chile. En cuanto al ranking nacional de cumplimiento de transparencia municipal el promedio general llega a más del $50 \%$.

- Departamento de transparencia municipal: Se refiere a la existencia de un departamento municipal exclusivo en temas de transparencia. La información fue extraída desde la estructura orgánica de los municipios de Chile. Es una variable binaria con valor 1 si el municipio cuenta con un departamento de transparencia comunal y valor 0 si el municipio no cuenta con aquello.

En tercer lugar, las variables de tipo demográfico que se utilizaron para esta investigación son las siguientes:

- Tipo de municipio, según tipología de la Subsecretaría de Desarrollo Regional y Administrativo (SUBDERE): Tipología comunal-municipal que busca recoger el máximo de variables que permitan reconocer diferencias entre territorios y entre administraciones locales, de manera de poder aplicar diferenciadamente estrategias públicas de apoyo a su desarrollo y buen desempeño (Subsecretaría de Desarrollo Regional y Administrativo, 2005). Esta variable se relaciona con los niveles de desarrollo comunal, los que se dividen en 5 grupos:

- Grupo 1: Grandes comunas metropolitanas con alto nivel de desarrollo y/o medio desarrollo. Contempla 47 municipalidades del país. 
- Grupo 2: Comunas mayores con desarrollo medio. Considera 37 municipalidades de Chile.

- Grupo 3: Comunas urbanas medianas con desarrollo medio. Cuenta con 56 municipalidades.

- Grupo 4: Comunas semi urbanas y rurales con desarrollo medio. Considera 96 municipalidades.

- Grupo 5: Comunas semi urbanas y rurales con bajo desarrollo. Contempla $109 \mathrm{mu}-$ nicipalidades de Chile.

La información se obtuvo desde el sitio web de la SUBDERE. Se crearon 5 variables binarias, la primera donde se le otorga valor 1 si el municipio está considerado dentro del Grupo 1 y 0 si es de otro grupo según la SUBDERE. La segunda binaria considera con valor 1 las comunas que sean parte del Grupo 2 y valor 0 caso contrario. La próxima variable binaria toma valor 1 si el municipio está dentro del Grupo 3 y de no ser así se le otorgó el valor 0. La siguiente variable toma valor 1 cuando la comuna integra el Grupo 4 y 0 si la comuna es de otro grupo. La última binaria toma valor 1 si el Municipio está considerado dentro del Grupo 5 y valor 0 si es caso contrario.

- Población total por comuna: Considerada como la cantidad de personas que viven en un espacio geográfico determinado, en este caso, una comuna. Información se extrajo desde la estimación de población 2016 del Instituto Nacional de Estadísticas (INE). La variable es de carácter numérica continua.

Alonso y García-García (2014), presentan en su investigación un análisis del tamaño de los municipios españoles concluyendo que, en los municipios con una población mayor a ciento veinte mil habitantes, el tamaño si resulta ser una variable explicativa del nivel de transparencia.

- Promedio edad comunal: Es una estadística que resume la distribución etaria de la población de una comuna. Los datos fueron extraídos por la Encuesta de Caracterización Socioeconómica (CASEN) del año 2013 y 2015. Esta variable es de carácter numérico continua, cuyo rango va de 0 a 1 (porcentaje).

Finalmente, las variables de tipo socioeconómica que se consideraron en la base de datos de esta investigación fueron las siguientes:
- Acceso a internet y conexión a banda ancha fija: Se conoce como conexión a internet al sistema de enlace mediante el cual los dispositivos móviles cuentan para conectarse a internet, lo que les permite visualizar las páginas web desde un navegador. A su turno, banda ancha en entendida como la elevada capacidad para transportar información que incide en la velocidad de transmisión de esta. Así entonces, es la transmisión de datos simétricos por la cual se envían simultáneamente varias piezas de información, con el objetivo de incrementar la velocidad de transmisión efectiva (Álvarez, 2010). Los datos comunales se extrajeron de la encuesta CASEN del año 2013 y 2015. Esta variable es de carácter numérico continua, cuyo rango va de 0 a 1 (porcentaje).

En la actualidad existen líneas de investigación (Alonso y García-García, 2014) que permiten explicar la relación existente entre la transparencia gubernamental y un set de característica sociodemográficas. En efecto, Alonso y García-García (2014) plantean que el uso del internet, como una herramienta de divulgación y canal de comunicación de datos de la administración pública, permite que la ciudadanía vea reducida la asimetría de información respecto a los gobiernos y sus administraciones internas y, en consecuencia, se construya una estrategia de lucha contra la corrupción y un empuje a favor de las buenas prácticas públicas.

- Promedio de escolaridad por comuna: Es el promedio de cursos aprobados por la población mayor de 15 años. La unidad de medida es en años. Los datos se obtuvieron de la encuesta CASEN del año 2013 y 2015 para cada comuna respectiva. Esta variable es de carácter numérico continua.

- Ingreso autónomo del hogar, por comuna: Es el resultado de la razón entre el producto total de una comuna en un determinado año y su número de habitantes (Ministerio de Hacienda, 2017). La información de esta variable se obtuvo por medio de las encuestas CASEN 2013 y 2015. Esta variable es de carácter numérico continuo.

- Índice de pobreza comunal: Se entiende como un indicador compuesto que mide las privaciones en tres dimensiones básicas del índice de desarrollo humano: una vida larga y saludable; conocimiento; y, un estándar decente de vida (Organización de Naciones Unidas (ONU), 1997). La información se obtuvo desde el Sistema Nacional de Información Municipal (SINIM) para el conjunto de años 2013-2014 y 
2015-2016. Esta variable es de carácter numérico continua, cuyo rango va de 0 a 1 (porcentaje).

"[L]a condición de acceso informatico a la comuna es un indicador que tiene correlación inversa con el nivel de pobreza comunal" (Chile Transparente, 2008: 45), ante ello se entiende que la Transparencia Municipal tiene una relación de aumento en el caso que el índice de transparencia de la comuna disminuya.

- Monto estimado de Fondo Común Municipal (FCM): Es el mecanismo de redistribución solidaria de los ingresos propios entre las municipalidades del país (artículo 122 de la Constitución Política). Estimación del total por año y la programación de pagos de los recursos correspondientes a anticipos del FCM e Impuesto territorial. Los datos fueron extraídos desde el sitio web del SINIM para los años 2014, 2015 y 2016 (año 2013 no disponible). Esta variable es de carácter número continuo, expresado en miles de pesos chilenos.

Los factores de carácter puramente económico o que reflejen la estructura productiva del municipio no han sido muy empleados en la literatura. Sin embargo, no deja de sorprender, ay que resulta evidente que otros factores de carácter social, financiero o presupuestario pueden verse influenciados por ellos, sufriendo los modelos econométricos resultantes de elevada endogeneidad.

De acuerdo con lo anterior, para esta investigación se generó una base de datos con las variables presentadas que se constituyen como variables independientes, como factores políticos, burocráticos, demográficos y socioeconómicos de las comunas y también como variable dependiente el cumplimiento del artículo $7^{\circ}$ de la Ley $\mathrm{N}^{\circ} 20.285$, el que integra las 13 disposiciones de ley presentadas al comienzo de este apartado. Dicha base de datos se construyó para los años 2013-2014-2015-2016, englobando todo el período alcaldicio 2012-2016.

Debe tenerse presente que la muestra incluyó los 345 municipios nacionales, sin embargo, 18 de éstos no contaban con sus sitios web actualizados, por lo que la muestra real pasó a ser de 327 municipios, todos con representación regional y nacional. No obstante, todas las variables independientes cuya información fue extraída de la CASEN, cuentan con una muestra para 324 municipios, por ende, gran parte de la investigación cuenta con un total de 324 observaciones para todas las variables.

En orden a analizar cada uno de los datos, se utilizaron dos modelos de análisis. El primero de ellos fue un análisis de correlación por medio de regresiones lineales, cuya correlación se midió respecto del porcentaje de cumplimiento de transparencia activa municipal y las variables independientes.

Las regresiones lineales están basadas en una técnica utilizada para estudiar la relación entre variables. En efecto, "[e]n la investigación estadística suele emplearse para pronosticar valores de una variable criterio ( $Y$ : dependiente) desde las puntuaciones de una variable predictora (X: independiente)" (Quezada, 2010: 209). El coeficiente de correlación lineal permite intuir si existe una relación entre las variables analizadas.

El modelo puede ser expresado como:

$$
Y_{T}=B_{0}+B_{1} X_{1}+B_{p} X_{p}+\epsilon
$$

El segundo modelo utilizado fue el de regresiones de Poisson, el cual puede ser entendido como un tipo especial de regresión donde la particularidad es que la variable dependiente se ajusta bien a una distribución que modela situaciones de conteo. Para este caso, se trata de la cantidad de disposiciones cumplidas por municipio.

La distribución de Poisson tiene un único parámetro, la lambda, que coincide con la Esperanza y la Varianza de la distribución. O sea, es una distribución que cuanto más grande es el valor esperado más dispersión tienen los valores que puede tomar la variable que se distribuya así (Llopis, 2013).

El modelo puede ser expresado como:

$$
I N(\lambda X=x)=a+\alpha_{1} X
$$

Ambas regresiones fueron realizadas por medio de un análisis de datos de panel, lo que se refiere a datos que combinan una dimensión temporal con otra transversal. Es decir, un conjunto de datos que recoge observaciones de un fenómeno a lo largo del tiempo como una serie longitudinal (Labra y Torrecillas, 2014).

El modelo de regresión común para un análisis de datos de panel puede ser expresado como:

$$
y_{n}=a_{i}+b x_{i t}+\epsilon_{i t}
$$

Finalmente, ambos tipos de regresiones utilizaron un intervalo de confianza del $95 \%$, lo cual se determina respecto de varios números, entre los cuales se estima que estará cierto valor desconocido con 
una determinada probabilidad de acierto. Un intervalo de confianza del $95 \%$ indica que el valor poblacional se encuentra en un determinado rango de valores con un $95 \%$ de certeza.

Los niveles de confianza más habituales para los intervalos son el de $95 \%$ y $99 \%$. En ese sentido, "[1]a elección de un nivel de confianza del 95\%, es un compromiso entre hacer declaraciones con una razonable probabilidad de acertar y que además el intervalo declarado, sea lo suficientemente pequeño como para suscitar algún interés" (Barón y Telléz, 2013: 13).

En base a la reciente exposición metodológica, se presentarán los resultados de la presente investigación.

\section{Resultados}

La información presentada a continuación, da cuenta de los resultados de los diferentes modelos econométricos construidos en orden a ratificar la hipótesis general presentada, la cual se concetra en que la política pública de transparencia activa municipal se ve condicionada por factores políticos, burocráticos, demográficos y socioeconómicos presentes en las comunas de Chile.

Las tablas que se agregan en este apartado, dan cuenta de la estadística descriptiva de las variables de cumplimiento que se utilizaron en esta investigación.

Respecto de los 18 municipios que no tenían sus sitios web habilitados y/o actualizados, éstos fueron considerados como si no cumplieran con ninguna disposición de la ley dentro de los cuatro años de evaluación.

Asimismo, el mínimo de disposiciones que se cumplieron para todos los años fueron 6 , donde menos del $1 \%$ de las municipalidades tuvo ese nivel de cumplimiento.

Para 2013, más de 70 municipios cumplieron con 10 disposiciones, siendo aquella la cantidad obtenida por la mayor número de municipios. En los años siguientes, el nivel de cumplimiento de transparencia activa aumentó a 13 disposiciones para gran parte de los municipios. En efecto, en 2014 fueron 82 municipalidades las que cumplieron con todas las disposiciones; en 2015, 160 municipios cumplieron con las 13 disposiciones; y, en 2016, fueron $222 \mathrm{mu}-$ nicipalidades las que obtuvieron las 13 disposiciones publicadas.

La Tabla № 1 presenta, en mayor detalle, la suma de cumplimiento de las disposiciones del artículo $7^{\circ}$ de la Ley $\mathrm{N}^{\circ} 20.285$ por parte de los municipios evaluados.

Seguidamente, la Tabla $N^{\circ} 2$ muestra las disposiciones de transparencia activa que obtuvieron mayor cumplimiento por parte de las municipalidades durante el periodo 2013-2016.

La disposición con $100 \%$ de cumplimiento fue la relativa a la publicación del marco normativo. La que le sigue en cumplimiento, obtuvo un $98 \%$ y se refiere a los mecanismos de participación ciudadana por cada comuna. Finalmente, la disposición que se encuentra en el tercer lugar de mayor cumplimiento, con $95 \%$, es la relacionada con la estructura orgánica de cada municipio.

En tercer lugar, en lo relativo a las disposiciones de la Ley $\mathrm{N}^{\circ} 20.285$ que presentaron menor cumplimiento por parte de los municipios, durante el periodo 2013-2016, se tiene que la disposición que obtuvo un bajo cumplimiento fue la publicación acerca del personal y sus remuneraciones, logrando solo un promedio de 259 municipios en publicarla. Seguidamente, otra disposición con bajo cumplimiento fue la de asignación de presupuesto, respecto de cual, 90 municipios, en promedio, no la cumplieron. Finalmente, la tercera disposición con menor cumplimiento fue la referente al diseño y el monto asignado de los subsidios, respecto de la cual solo 215 municipios, en relación a una muestra de 327 , la cumplieron en promedio de los cuatro años de evaluación, lo que significa un $65 \%$ de cumplimiento.

A continuación, se muestran los municipios que cumplieron con la mayor y menor cantidad de disposiciones de transparencia activa de manera constante. En efecto, el municipio que obtuvo el menor nivel de cumplimiento durante los cuatro años de evaluación fue la comuna de Alto Hospicio, cuyo cumplimiento se mantuvo constante en 6 disposiciones.

En relación a los municipios que obtuvieron un $100 \%$ de cumplimiento durante todo el periodo alcaldicio analizado, se verificaron 50 , los cuales se detallan en la Tabla $\mathrm{N}^{\circ} 4^{4}$.

La siguiente tabla muestra las variables independientes utilizadas en esta investigación. En efecto, la Tabla № 5 da cuenta de las variables tanto políticas, burocráticas, demográficas y socioeconómicas de los distintos municipios analizados, para los años 2013-2014-2015-2016, con objeto de observar los

\footnotetext{
4 Para efectos de examinar los datos relativos al cumplimiento de cada uno de los municipios de Chile respecto a las disposiciones del artículo $7^{\circ}$ de la Ley $\mathrm{N}^{\circ} 20.285$, véase Kretschmer (2017).
} 
Tabla 1: Cumplimiento de disposiciones por año

\begin{tabular}{lllllllll} 
Cumplimiento & 2013 & $\%$ & 2014 & $\%$ & 2015 & $\%$ & 2016 & $\%$ \\
disposiciones & & & & & & & & \\
\hline 0 & 18 & 5,22 & 18 & 5,22 & 18 & 5,22 & 18 & 5,22 \\
1 & 0 & 0,00 & 0 & 0,00 & 0 & 0,00 & 0 & 0,00 \\
2 & 0 & 0,00 & 0 & 0,00 & 0 & 0,00 & 0 & 0,00 \\
3 & 0 & 0,00 & 0 & 0,00 & 0 & 0,00 & 0 & 0,00 \\
4 & 0 & 0,00 & 0 & 0,00 & 0 & 0,00 & 0 & 0,00 \\
5 & 0 & 0,00 & 0 & 0,00 & 0 & 0,00 & 0 & 0,00 \\
6 & 4 & 1,16 & 2 & 0,58 & 2 & 0,58 & 1 & 0,29 \\
7 & 17 & 4,93 & 15 & 4,35 & 5 & 1,45 & 2 & 0,58 \\
8 & 33 & 9,57 & 25 & 7,25 & 21 & 6,09 & 7 & 2,03 \\
9 & 61 & 17,68 & 45 & 13,04 & 16 & 4,64 & 8 & 2,32 \\
10 & 72 & 20,87 & 51 & 14,78 & 33 & 9,57 & 8 & 2,32 \\
11 & 49 & 14,20 & 52 & 15,07 & 34 & 9,86 & 10 & 2,90 \\
12 & 36 & 10,43 & 55 & 15,94 & 56 & 16,23 & 69 & 20,00 \\
13 & 55 & 15,94 & 82 & 23,77 & 160 & 46,38 & 222 & 64,35 \\
Totales & 345 & 100 & 345 & 100 & 345 & 100 & 345 & 100 \\
\hline
\end{tabular}

Tabla 2: Disposiciones con mayor cumplimiento

\begin{tabular}{lll} 
Disposición & $\begin{array}{l}\text { Cantidad de muni- } \\
\text { cipios que la cum- } \\
\text { plen }\end{array}$ & $\begin{array}{l}\text { Porcentaje de cum- } \\
\text { plimiento }\end{array}$ \\
\hline $\begin{array}{l}\text { Marco normativo } \\
\text { Mecanismos de par- }\end{array}$ & 327 & $100 \%$ \\
ticipación ciudadana & $325 \%$ \\
Estructura orgánica & 322 & $98 \%$ \\
\hline
\end{tabular}

Fuente: Elaboración propia

cambios en las diversas variables.

En primer lugar, se tiene que el porcentaje de participación electoral por comuna se redujo de un año electoral al otro, logrando una media del más del $50 \%$ en las elecciones municipales del año 2013, y reduciéndose al $25 \%$ de participación para las elecciones locales del periodo siguiente.

Seguidamente, relacionado a los partidos políticos del alcalde, se observa que un $26 \%$ de las autoridades comunales son respaldados por partidos de derecha, el $43 \%$ de izquierda y el resto fueron elegidos sin tener un partido apoyándoles, es decir, de manera independiente.

Tercero, se tiene la cantidad de concejales promedio que tienen los municipios, lo cual demuestra que, en promedio, hay 6 concejales por comuna, razón por la cual es posible interpretar que gran parte de las comunas del país cuentan con menos de setenta mil electores.

En cuarto término, la variable que sigue muestra la cantidad de períodos que han ejercido los diferentes alcaldes de las comunas evaluadas. En ese contexto, hay alcaldes que llevan un sólo periodo, como es el caso de Conchalí, Algarrobo, Cabrero,
Parral, entre otros, pero hay otros que están ejerciendo su séptimo período como autoridades comunales, tales como sucede con los de Laguna Blanca y Río Verde. El promedio de la cantidad de periodos ejercidos por los ediles comunales es de 2 .

Quinto, respecto de la reelección de los alcaldes, un $50 \%$ de las comunas volvieron a elegir a sus alcaldes en el periodo 2012-2016.

En sexto lugar, en relación al sexo de los ediles, la media es de $0,88 \%$, lo cual significa que es más común que haya alcaldes varones a alcaldesas mujeres, esto considerándolo que el valor 0 representa a alcaldesa y valor 1 si el edil es hombre.

En promedio, el $18 \%$ de las municipalidades de Chile cuenta con un departamento de transparencia, esto significa que solo 63 municipalidades de 345 .

Por último, el monto estimado de aporte al Fondo Común Municipal por parte de las comunas, tuvo en promedio el año 2013 un valor de 2.485.808, el cual para el año 2016 incrementó a 3.456.682.

Acerca de la categoría de desarrollo comunal otorgada por la SUBDERE, se puede estimar que 


\begin{tabular}{lll}
\multicolumn{2}{c}{ Tabla 3: Disposiciones con menor cumplimiento } \\
Disposición & $\begin{array}{l}\text { Cantidad de muni- } \\
\text { cipios que la cum- } \\
\text { plen }\end{array}$ & $\begin{array}{l}\text { Porcentaje de cum- } \\
\text { plimiento }\end{array}$ \\
& 259 & $79 \%$ \\
\hline $\begin{array}{l}\text { Planta de personal } \\
\text { Presupuesto asigna- }\end{array}$ & 237 & $72 \%$ \\
do & & $65 \%$ \\
$\begin{array}{l}\text { Diseño y monto sub- } \\
\text { sidios }\end{array}$ & 215 &
\end{tabular}

Fuente: Elaboración propia

Tabla 4: Municipalidades con $\mathbf{1 0 0 \%}$ de cumplimiento de transparencia activa durante el periodo alcaldicio 2012-2016

$\begin{array}{lllll}\text { Ancud } & \text { Galvarino } & \text { Laja } & \text { Los Lagos } & \text { Recoleta } \\ \text { Arica } & \text { Hualañé } & \text { Las Condes } & \text { Macul } & \text { Río Hurtado } \\ \text { Cabrero } & \text { Huechuraba } & \text { Lebu } & \text { Mafil } & \text { San Fernando } \\ \text { Castro } & \text { Iquique } & \text { Limache } & \text { Melipilla } & \text { San Javier } \\ \text { Cerro Navia } & \text { La Calera } & \text { Linares } & \text { Pedro Aguirre Cerda } & \text { Temuco } \\ \text { Chiguayante } & \text { La Cisterna } & \text { Litueche } & \text { Puchuncaví } & \text { Tucapel } \\ \text { Contulmo } & \text { La Pintana } & \text { Llay-Llay } & \text { Puente Alto } & \text { Victoria } \\ \text { Curacaví } & \text { La Reina } & \text { Lo Barnechea } & \text { Punitaqui } & \text { Vilcún } \\ \text { Fresia } & \text { La Serena } & \text { Lo Prado } & \text { Quillón } & \text { Vitacura } \\ \text { Futrono } & \text { La Union } & \text { Longaví } & \text { Quintero } & \text { Yerbas Buenas }\end{array}$

Fuente: Elaboración propia

$14 \%$ de las comunas de Chile corresponden al grupo $1,11 \%$ al grupo $2,16 \%$ están dentro del grupo $3,28 \%$ están en la categoría número 4 y finalmente el $31 \%$ es parte del grupo número 5 .

Sobre la identificación territorial de las comunas del país, existe una diferencia mínima entre las municipalidades que son urbanas y las rurales, ya que el promedio de urbanismo es de $51 \%$ en todo Chile.

El promedio de pobreza comunal para los años 2013-2014 fue de 15,88\% pero, para el año el periodo 2015-2016 el promedio de pobreza comunal alcanzó un $21 \%$.

Acerca del ingreso autónomo por hogar, se puede observar que el promedio para el 2013 era de 619 mil pesos chilenos, y para el 2016 fue cercano a 710 mil pesos chilenos.

El promedio del puntaje de fiscalización del CPLT subió de $47 \%$ a $77 \%$, entre los años 2013 y 2016, lo que significa que los municipios del país tuvieron un mejor rendimiento en la evaluación del Consejo.

La población comunal estimada en promedio fue cercana a los 50 mil habitantes.

Las siguientes variables dice relación al promedio de edad de las comunas del país, cuyo promedio máximo para el año 2013 llega a los 47 años y para el 2016 sube dos años llegando a 49 años de edad. Eso significa que paulatinamente el promedio de edad de la población chilena está subiendo, pasando de 36,7 años en 2013 a casi 38 en los siguientes tres años (INE, 2017)

En cuanto a los años de escolaridad promedio de las comunas del país, esta se mantiene constante durante los años de evaluación, logrando un promedio de 9,45 años de escolaridad promedio en 2013 y 9,74 años durante el 2016.

Para el año 2013 y 2014 el promedio de hogares que tenían acceso a banda ancha fija por comuna era de $19 \%$, pero para el año 2016 esta variable se triplicó llegando a más del $60 \%$ el promedio de los hogares que tenían acceso a banda ancha fija en Chile.

A continuación se detallarán los resultados de las regresiones lineales y regresiones de Poisson desarrolladas para medir la relación existente entre la política pública de transparencia activa plasmada en la Ley № 20.285 y factores comunales.

Primero se señalarán los resultados de las regresiones lineales de panel, las cuales las variables independientes demuestran la existencia de elementos incidentes en el porcentaje de cumplimiento de transparencia activa de los municipios de Chile durante el periodo alcaldicio comprendido entre 20122016. Entre las más de veinte variables independientes utilizadas, hubo 9 significativas. 
Tabla 5: Descripción de variables independientes

\begin{tabular}{|c|c|c|c|}
\hline Variable & Observación & Media & Desviación estándar \\
\hline Padrón electoral municipal 2013-2014-2015 & 345 & 38.895 & 56.440 \\
\hline Padrón electoral municipal 2016 & 345 & 77.790 & 112.880 \\
\hline Porcentaje participación electoral comunal 2013-2014- 2015 & 345 & $53,23 \%$ & $11,92 \%$ \\
\hline Porcentaje participación electoral comunal 2016 & 345 & $25,07 \%$ & $8,55 \%$ \\
\hline Partido político del alcalde (derecha) & 343 & $26,24 \%$ & $44,06 \%$ \\
\hline Partido político del alcalde (izquierda) & 345 & $43,19 \%$ & $49,61 \%$ \\
\hline Partido político del alcalde (independiente) & 345 & $29,86 \%$ & $45,83 \%$ \\
\hline Cantidad de concejales por comuna & 345 & 6 & 1 \\
\hline Periodos por alcalde & 345 & 2 & 1 \\
\hline Incumbencia del alcalde & 345 & $50 \%$ & $50 \%$ \\
\hline Sexo del alcalde & 345 & 0,88 & 0,32 \\
\hline Departamento de transparencia & 332 & 0,18 & 0,38 \\
\hline Monto estimado aporte FCM 2013 & 345 & $\$ 2.485 .808$ & $\$ 3.342 .247$ \\
\hline Monto estimado aporte FCM 2014 & 345 & $\$ 2.750 .712$ & $\$ 3.641 .621$ \\
\hline Monto estimado aporte FCM 2015 & 345 & $\$ 3.115 .304$ & $\$ 4.103 .727$ \\
\hline Monto estimado aporte FCM 2016 & 345 & $\$ 3.456 .682$ & $\$ 4.495 .624$ \\
\hline Comunas grupo SUBDERE 1 & 345 & 0,14 & 0,34 \\
\hline Comunas grupo SUBDERE 2 & 345 & 0,11 & 0,32 \\
\hline Comunas grupo SUBDERE 3 & 345 & 0,16 & 0,37 \\
\hline Comunas grupo SUBDERE 4 & 345 & 0,28 & 0,45 \\
\hline Comunas grupo SUBDERE 5 & 345 & 0,31 & 0,46 \\
\hline Comuna urbana-rural & 324 & 0,51 & 0,50 \\
\hline Pobreza comunal 2013-2014 & 345 & $15,88 \%$ & $7,71 \%$ \\
\hline Pobreza comunal 2015-2016 & 345 & $21,05 \%$ & $10,94 \%$ \\
\hline Ingreso autónomo por hogar 2013-2014 & 343 & $\$ 619.213$ & $\$ 379.154$ \\
\hline Ingreso autónomo por hogar 2015-2016 & 324 & $\$ 709.871$ & $\$ 409.635$ \\
\hline Puntaje fiscalización CPLT 2013 & 345 & $47 \%$ & $27 \%$ \\
\hline Puntaje fiscalización CPLT 2014 & 345 & $56 \%$ & $22 \%$ \\
\hline Puntaje fiscalización CPLT 2015 & 345 & $65 \%$ & $21 \%$ \\
\hline Puntaje fiscalización CPLT 2016 & 345 & $77 \%$ & $17 \%$ \\
\hline Población comunal estimada 2013-2016 & 345 & 52.730 & 81.939 \\
\hline Edad promedio comunal 2013-2014 & 324 & 37 & 2,82 \\
\hline Edad promedio comunal 2015-2016 & 324 & 38 & 2,81 \\
\hline Escolaridad promedio comunal 2013-2014 & 324 & 9 & 1,40 \\
\hline Escolaridad promedio comunal 2015-2016 & 319 & 10 & 1,27 \\
\hline Conexión banda ancha fija por hogar 2013-2014 & 324 & $19 \%$ & $16 \%$ \\
\hline Conexión banda ancha fija por hogar 2015-2016 & 324 & $61 \%$ & $18 \%$ \\
\hline
\end{tabular}

Fuente: Elaboración propia

La primera variable significativa es el porcentaje de participación electoral comunal. El resultado que arrojó la regresión fue que por cada punto porcentual que aumente la participación electoral, el cumplimiento de transparencia activa municipal disminuye en $0,2 \%$.

La situación puede ser explicada con que la transparencia activa se extrae por medio de los sitios webs de las municipalidades, y la conexión y acceso a esta información no necesariamente se enfoca en la participación ciudadana. Tal como se refiere el profesor de la Universidad Alberto Hurtado, Nicolás Inostroza "si consideramos las bajas tasas de aprobación al sistema político y participación ciudadana en las elecciones [...] las posibilidades que ofrece el gobierno electrónico como medio para ampliar la participación y probidad, veremos que existe un potencial que hasta ahora no se ha utilizado adecuadamente" (Inostroza, 2015: 119).

La segunda variable significativa es la cantidad de concejales que tiene un municipio, los cuales pueden ser 6,8 o 10 dependiendo la cantidad de electores por comuna. El resultado indica que por cada concejal extra que tiene una comuna, el porcentaje de cumplimiento de transparencia activa municipal se reduce en $2,6 \%$.

Esto se puede comprender desde la responsabilidad que tienen los concejales en ejercicio de hacer rendición de cuentas, mientras menos son, menos 
procesos tiene que pasar la Municipalidad en generar este proceso público. La publicación de las audiencias, viajes y donativos que las autoridades comunales que deberían a comenzar a registrar constituye un instrumento de alta importancia tanto para los ciudadanos como para sus representantes. Esta norma permitirá democratizar el acceso a las autoridades y transparentar el lobby (Consejo Para la Transparencia, 2015).

La siguiente variable significativa fue la cantidad de periodos de un alcalde. El resultado muestra que por cada periodo extra, comenzando en uno, que el alcalde lleve como autoridad comunal, el cumplimiento de transparencia activa municipal se reduce en $1,2 \%$.

El año 2015 se multaron a 92 alcaldes de un total de 196 por incumplir la Ley de Transparencia. A la vez, el Observatorio Electoral de la Universidad Diego Portales establece que en el 2000 la cantidad de alcaldes que fueron a reelección llegó a una cifra de $90,3 \%$ y cada elección aumenta más. Este fenómeno se puede evidenciar ya que al llevar más años en el cargo, las autoridades están concentradas en mantener al electorado a su favor y priorizar las acciones que le permitan seguir en el cargo, es decir no tienen incentivos para mostrar transparencia, ya que saben que van a ser reelectos.

El puntaje de Fiscalización del CPLT, también fue significativa. Esto demuestra que por cada punto porcentual que sube el promedio de puntaje de fiscalización del estudio del CPLT, el cumplimiento de transparencia activa de los municipios de Chile aumenta en $3,6 \%$.

El CPLT al ser el órgano fiscalizador del cumplimiento de la Ley № 20.285 a las distintas instituciones públicas, realiza actividades controladoras por medio de un calendario anual. A la vez, está establecido que el CPLT tiene dentro de sus funciones legítimas la capacidad de aplicar sanciones y tramitar sumarios en el caso en que los órganos públicos presenten reiteradas infracciones a la Ley (Consejo Para la Transparencia, 2011).

Por tanto, esto puede entender la correlación que existe con el comportamiento que tienen las municipalidades del país ante el cumplimiento de transparencia activa, ya que cómo órganos públicos sus recursos son limitados y no tienen la capacidad para designar dinero para el pago de multas, buscan cumplir con la responsabilidad que les compete según lo establecido en la ley y evitarse las fiscalizaciones que les pueden perjudicar su funcionamiento.

La caracterización demográfica de la SUBDERE tuvo dos variables significativas, las cuales arrojaron que por cada municipio que aumente su nivel de desarrollo y se identifique en el grupo 3, su porcentaje de disposiciones de transparencia activa cumplidas se reduce en $4,5 \%$. También, por cada municipio que aumente su nivel de desarrollo y sea catalogado en el grupo SUBDERE 4, su porcentaje de cumplimiento de transparencia municipal disminuye en $0,9 \%$.

La sexta variable significativa dice relación al promedio de edad comunal, la cual los resultados arrojan que por cada año que aumenta la edad promedio de las comunas, el nivel de cumplimiento de transparencia activa municipal se reduce en $0,1 \%$.

El informe mensual de julio del 2015 desarrollado por el CPLT, arrojó que de los datos de personas que más hacen solicitudes de transparencia a los órganos públicos son las personas de entre 3049 años, pero que pasado los 50 cae abruptamente la cantidad de solicitudes que se realizan (CPLT, 2015). El promedio de edad comunal es de 37 años (según la CASEN 2015), por ende se puede verificar que mientras pasado el rango etario de entre 30-49 la cantidad de información que pide la ciudadanía disminuye.

Otra variable significativa de este tipo de regresión es el nivel de escolaridad promedio de la comuna, es decir, por cada año que aumenta el promedio de escolaridad comunal, el nivel de cumplimiento de la política pública de transparencia activa municipal disminuye en $0,004 \%$.

El mismo estudio del CPLT, muestra también la cantidad de solicitudes que hacen las personas según su nivel de escolaridad, la que demuestra que gran parte la realizan las personas con educación técnica y/o profesionales con un promedio de 1037 solicitudes mensuales de transparencia activa a los organismos públicos, sin embargo, las personas cuyo nivel de escolaridad supera los 15 años, disminuye considerablemente la cantidad de solicitudes, teniendo un promedio de 660 solicitudes de transparencia activa (CPLT. 2015).

La última variable significativa es el índice de pobreza comunal, lo que detalla que por cada punto porcentual que sube en índice de pobreza de la comuna, la porcentaje de cumplimento de transparencia activa municipal aumenta en $0,29 \%$.

Por otro lado, las regresiones de Poisson, las cuales las variables independientes dan a conocer la existencia de relación con la cantidad de disposiciones cumplidas por transparencia activa por los municipios del país. Las variables significativas se detallan a continuación, de las cuales algunas se repiten del análisis presedente.

La primera variable significativa al igual que las 
regresiones lineales es el porcentaje de participación electoral comunal, el cual indica que por cada punto porcentual que aumente la participación electoral por comuna, el cumplimiento de transparencia activa municipal se reduce en 0,35 disposiciones de ley.

La siguiente variable significativa es la cantidad de periodos que lleva un alcalde dirigiendo la comuna, lo que demuestra que por cada periodo extra que lleve el edil como autoridad municipal, la cantidad de disposiciones de ley cumplidas por transparencia activa se reduce en 3,29 .

La tercera variable significativa al igual que en el análisis de regresiones lineales, mostró que por cada punto que aumente el promedio de puntaje de fiscalización del CPLT, aumentan en 3,4 las disposiciones de ley cumplidas por transparencia activa por los municipios de Chile.

La próxima variable que arrojó resultado significativo, fue la categorización de SUBDERE en el grupo 4, lo que significa que por cada municipalidad que entra en este grupo, se reduce en 4 la cantidad de disposiciones de ley cumplidas por municipio.

La quinta variable significativa es la edad promedio de la comuna, lo que detalla que por cada año que suba la edad promedio comunal, la cantidad de disposiciones de transparencia activa cumplidas por municipio disminuye en 0,6 .

En cuanto a la escolaridad promedio, está también es significativa, lo que demuestra que por cada año que aumente la escolaridad promedio por comuna, la cantidad de disposiciones cumplidas de transparencia activa se reduce en 1,9.

La siguiente variable significativa es la conexión a banda ancha fija de los hogares, la cual demuestra que por cada punto porcentual que aumente la conexión a internet de los hogares por comuna, la transparencia activa aumenta en 2,5 disposiciones su complimiento.

Se comprende desde la perspectiva jurídica de que por ley toda la información de transparencia activa debe ser publicada por los sitios webs oficiales de los órganos públicos, por ende, los municipios tienen responsabilidad ante este acto. Pero a al vez la conexión a internet orienta las definiciones hacia la administración (TIC) y el gobierno, destacando las trasformaciones que originan las tecnologías de información en las relaciones entre el gobierno, ciudadanos, empresas y otras entidades gubernamentales. El foco central, es el uso de TIC como herramientas para alcanzar objetivos como la eficiencia o combatir vicios como la corrupción (Inostroza, 2015)
La última variable significativa medida por regresiones de Poisson, fue el índice de pobreza comunal, lo que demuestra que por cada punto porcentual que aumenta el índice de nivel de pobreza por comuna, la cantidad de disposiciones cumplidas de transparencia activa se reduce en 0,34 .

Esto se puede comprender desde la perspectiva de que hay una desviación de los recursos hacía los esfuerzos de superar la pobreza, reforzando la entrega de subsidios y beneficios que le den posibilidades de tener una vida más ligera a los ciudadanos. "los efectos de la transparencia en la mitigación de la desigualdad social son marginales, si se compara con la magnitud del reto, que es estructural y, lamentablemente, cuenta con raíces profundas. La pobreza extrema es profunda, sobre todo para quien la padece, y mancha cualquier cifra de crecimiento económico" (Matute, 2016).

Todo el análisis anterior es resumido en la tabla № 6 .

\section{Conclusiones y recomendacio- nes finales}

El reto de la política pública de transparencia municipal es alcanzar una gestión íntegra de la probidad en los gobiernos locales, con el objeto de prevenir comportamientos contrarios a ella, como son la corrupción y la malversación de fondos. Éste se refiere, ante todo, a la necesidad de cambiar el tipo de rendición de cuentas en las municipalidades, motivando así transformaciones en los comportamientos de gestión. Tales cambios se podrían producir por la renovación de ciertos criterios políticos, burocráticos, demograficos y socioeconómicos de las comunas, para así entregar condiciones que generen posibles transformaciones en los resultados de cumplimiento de transparencia activa municipal.

La teoría de principal-agente y accountability permiten comprender la relaciòn de información de asimetria existente entre los actores de la transparencia municipal, ya que, si bien es la ley la que le entrega responsabilidad al CPLT de fiscalizar, los municipios, los son los únicos organismos que pueden acceder, de forma primaria, a la información referente a su gestión interna, es pos de disminuir la brecha de información y permitir una mejor gestiòn democràtica en su rol característico de funcionamiento y desarrollo de la política pública de transparencia.

Si bien el espacio desarrollado de la política pública de transparencia puede ser comprensible desde la perspectiva teórica, el funcionamiento 
Tabla 6: Resultados de regresiones sobre el nivel de cumplimiento de transparencia activa municipal

\begin{tabular}{lcc} 
& Coef. Reg. Lineal & Coef. Reg. Poisson \\
\hline Padrón electoral comunal & -.000 & -.000 \\
Participación electoral comunal &,$- 002^{*}$ &,$- 004^{*}$ \\
Partido político del alcalde (derecha) & .01 & .16 \\
Partido político del alcalde (izquierda) & .11 & .17 \\
Partido político del alcalde (independiente) & .094 & .15 \\
Cantidad de concejales &,$- 027^{*}$ & -.059 \\
Periodos por alcalde &,$- 012^{*}$ &,$- 033^{*}$ \\
Incumbencia del alcalde & -.14 & -.22 \\
Sexo del alcalde & -.114 & -.17 \\
Puntaje fiscalización CPLT &, $037^{*}$ &, $035^{*}$ \\
Comunas grupo SUBDERE 1 & -.069 & -.167 \\
Comunas grupo SUBDERE 2 & -.065 & -.132 \\
Comunas grupo SUBDERE 3 &,$- 045^{*}$ & -.01 \\
Comunas grupo SUBDERE 4 &,$- 009^{*}$ &,$- 04^{*}$ \\
Departamento transparencia & -.073 & -.13 \\
Comuna urbano-rural & -.05 & -.09 \\
Población comunal & -.00 & -.00 \\
Edad promedio comunal &,$- 001^{*}$ &,$- 007^{*}$ \\
Escolaridad promedio comunal &,$- 00004^{*}$ &,$- 0195^{*}$ \\
Conexión banda ancha fija por hogar & .076 &, $025^{*}$ \\
Ingreso autónomo por hogar & -.00 & -.00 \\
Pobreza comunal &, $003^{*}$ &,$- 003^{*}$ \\
Monto estimado aporte FCM & .00 & -.00 \\
\hline
\end{tabular}

Fuente: Elaboración propia

práctico permite apreciar, en la aplicabilidad de la ley, el verdadero proceso y resultados de la política pública evaluada.

Con respecto a la hipótesis general planteada al principio de esta investigación, la cual estableció que la política pública de transparencia activa municipal estaba condicionada por factores políticos, burocráticos, demográficos y socioeconómicos de las comunas de Chile, es posible concluir que ésta se verifica. En efecto, se demostró por medio de dos tipos de regresiones, tanto lineales, así como de Poisson, que la política pública de cumplimiento de la transparencia activa de la mayoría de los municipios de Chile depende de un set de características que son innatas de las comunas.

En ese orden de ideas, la participación electoral por comuna reveló generar un impacto tanto en el porcentaje de cumplimiento de la política pública de transparencia activa como en la cantidad de disposiciones cumplidas, asimilando que mientras más aumenta la participación en las urnas, la transparencia municipal disminuye. Quizás, comúnmente se piense que los electores asisten a votar por un sentimiento de deber y derecho, con el propósito de sacar a los malos políticos de sus cargos. Sin embargo, lo que realmente ocurre es que los electores del siglo XXI han aumentado sus exigencias y pretenden ver la gestión de las autoridades políticas en cuestiones concretas como es la mejora en la infraestructura, los centros de salud o los espacios públicos, mas que, en lenguaje popular, si se roban la plata o no (Garcia-Garrido, 2017).

La variable antes mencionada tiene un rol político dentro del resultado de la política pública de transparencia activa municipal.

Asimismo, se verificó que la cantidad de periodos que lleva un alcalde como autoridad tiene cierto efecto en el grado de cumplimiento de transparencia activa de los municipios, ya que cuanto más periodos lleva un alcalde en ejercicio, menos propensión al cumplimiento de disposiciones de Ley № 20.285 tendrá dicho municipio. Este resultado también es de carácter político.

El antes dicho resultado no deja de ser interesante, ya que hace un llamado a la necesidad de revisar la ley orgánica constitucional de municipalidades, en orden a generar un límite de periodos en que pueden ejercer tanto los alcaldes y los concejales, para permitir, al mismo tiempo, a otras personas ingresar al servicio público por medio de elección popular, incentivando que el triunfo se logre por medio de la gestión de transparencia del municipio, en desmedro que aquel se logre por una cuota de clientelismo. 
Por otro lado, se tiene que existe una variable de carácter burocrática que produce significancia en el resultado de comportamiento de la política pública de transparencia activa municipal, cual es el puntaje de fiscalización del estudio del CPLT, consistente en un acto de control, que se verifica en un proceso al que son sometidos todos los municipios de Chile.

Además, esta investigación evidenció que hay variables de naturaleza demográfica de las comunas que son significativas a la hora de evaluar la política pública de transparencia activa de los municipios del país. La clasificación de las comunas según nivel de urbanismo y desarrollo, realizada por la SUBDERE, así como la edad promedio por comuna, cuentan con una cuota de significancia.

En efecto, el grupo 4, según la SUBDERE, categoriza a las comunas semiurbanas y con desarrollo medio, las cuales cuentan con recursos limitados y con altas demandas y necesidades de sus habitantes, situación por la cual aquellas buscan la mejora de la infraestructura e interconexión con las grandes ciudades, el resguardo de la salud mediante la construcción y/o habilitación de centros médicos que se acomoden a la cantidad de habitantes, por lo que la transparencia no está dentro de las prioridades.

Por otra parte, el promedio de edad de los habitantes de la comuna fue también una variable que tuvo significancia en esta investigación, condicionada como un factor demográfico, que permite demostrar que la edad promedio de las personas que viven en las diversas comunas a la vez constituye el ideal de que la edad cada vez más alta no necesariamente aumenta la transparencia activa municipal. Ello se puede comprender ya que a las personas de más edad les es más difícil utilizar las tecnologías de información mediante las cuales, precisamente, se investiga y analiza el cumplimiento de la transparencia activa.

Por último, se tienen dos variables de carácter socioeconómico que se erigen como significativas, cuales son la escolaridad promedio y el índice de pobreza de la comuna, la cual es posible combatirla utilizando los medios de comunicación, ya que "[l]os medios de comunicación abiertos y libres pueden desempeñar un papel primordial en la lucha contra la pobreza" (Unesco, 2014). En consecuencia, es posible afirmar que la transparencia activa de las municipalidades no es un método de reducción de la pobreza.

Como se aprecia de lo antes señalado, esta investigación tuvo como objetivo principal el analizar la información de transparencia activa de todos los municipios de Chile durante un periodo prolongado de 4 años (2013-2014-2015-2016), lo que permi- tió construir una base de datos que integra toda la información publicada por los gobiernos locales del país, la que ha permitido determinar cuáles son los factores que realmente se correlacionan en el cumplimiento de la política pública de transparencia activa municipal.

De esa forma, esta investigación no es más que un llamado a dilucidar qué es lo que incide en el cumplimiento de la Ley № 20.285 y cuáles son los incentivos, desde la perspectiva teórica, así como también desde una perspectiva política, burocrática, demográfica y económica, para cumplir con la política pública que se orienta a tener gobiernos locales más transparentes, considerando así que un buen gobierno abarca nociones como las de mayor participación de la sociedad civil en la toma de decisiones públicas, generando la instauración de un Estado de derecho más sólido, en aras a luchar contra la corrupción y permitiendo la reducción de la pobreza y la promoción y el respeto de los derechos humanos (Unesco, 2014).

Finalmente, se hace imperioso señalar que, en orden a que la política pública de transparencia municipal tome total relevancia tanto dentro del sistema político como administrativo del país, es necesario otorgarle verdadera autonomía a los municipios, lo cual debe estar unido a que el CPLT ejerza potestades fiscalizadores y pueda realizar convenios de colaboración con los entes municipales, en pos de entregarle las más bastas capacidades técnicas y administrativas, con el objeto de alcanzar altos grados de probidad a tales gobiernos locales.

La situación antes dicha no es, ni puede ser, un esfuerzo aislado de un gobierno, sino que, para ser materializada, es necesario el apoyo de todos los actores políticos del país, pues tales son los encargados hacer efectiva aquella iniciativa, dando, primeramente, el ejemplo con su actuar e incentivando, a través de sus propios actos, la transparencia en el servicio público.

\section{Referencias}

Alonso, M. L. y García-García, J. (2014). Evaluación de la transparencia municipal en el Principado de Asturias. Auditoría Pública, 64:75-86.

Álvarez, C. L. (2010). Diccionario de Derecho de la Información.

Arjona, L. A. (2005). Accountability en México desde la Teoría Agente-Principal. México: Universidad Veracruzana.

Avilés, V. (2009). Principios De La Probidad, Pu- 
blicidad Y Transparencia En Los Actos De Los Organismos Del Estado.

Barón, F. y Telléz, F. (2013). Intervalos de confianza.

Cárcaba García, A. I. y García García, J. (2010). Determinants of online reporting of accounting information by Spanish local government authorities. Local Government Studies.

Chile Transparente (2008). Estándar de Transparencia Municipal. Convenio Asociación Chilena de Municipalidades.

Consejo Asesor Presidencial contra los Conflictos de Interés, e. T. d. I. y. l. C. (2015). Informe Final.

Consejo Para la Transparencia (2011). Estudio Nacional de Transparencia.

Consejo Para la Transparencia (2014). Resultados fiscalizacion 2014 transparencia activa.

Consejo Para la Transparencia (2015). Informe Mensual de estadísticas, julio 2015.

De León, P. (2008). Hacia un concepto de transparencia: Orígenes e Importancia. Recuperado de http://ca-bi. com/blackbox/wpcontent/uploads/downloads/2012/08/Transparencia1. $p d f$.

Delgado, F. y Radio Bio Bio (2015). Cinco hechos de corrupción que impactaron al país antes del caso Penta en los últimos 15 años.

Fuenmayor, A. (2004). El derecho de acceso de los ciudadanos a la información pública: análisis jurídico y recomendaciones para una propuesta de ley modelo sobre el derecho de acceso de los ciudadanos a la información pública.

Garcia-Garrido, F. (2017). El procedimiento de toma de decisiones y las organizaciones regulatorias globales: nuevas formas de administración y poder. Public Policy Portuguese Journal, 2(1):2856 .

Gorbaneff, Y. (2003). Teoría del agente-principal. Revista Universidad EAFIT, 129:75-87.

Inostroza, N. (2015). Índice de Participación Electrónica Municipal: Gobierno Electrónico Local en la Región Metropolitana. Búsquedas Políticas, 4(1):113-135.
Labra, R. y Torrecillas, C. (2014). Cátedra UAMAccenture en economía y gestión de la innovación.

Ley № 18.695 (2006).

Ley № 20.285 (2008).

Llopis, J. (2013). La estadística: una orquesta hecha instrumento. Cursos de Estadística.

Matute, C. (2016). La relación entre pobreza y transparencia.

Monckeberg, M. (2015). La Máquina para defraudar: los casos de Penta y Soquimich. Pinguin Random, Santiago.

Organización de Naciones Unidas (ONU) (1997). Parámetros del índice de desarrollo humano.

Precht, A. (2017). Índice de Transparencia de Partidos Políticos: informe 2017.

Quezada, N. (2010). Metodología de la Investigación: Estadística Aplicada en la Investigación. Macro E.I.R.L, Lima.

Sartori, G. (1980). Partidos y sistemas políticos. Marco para un análisis. St. Martin's Press.

Schedler, A., Diamond, L. J., y Plattner, M. F. (1999). The self-restraining state: power and accountability in new democracies. Lynne Rienner Publishers.

Silva, E. y Meléndez, C. (2011). En búsqueda del Principal: nueva definición de la relación principal-gente en el Plan Piloto de Reforma de la Gestión para fortalecer el vínculo SubsecretarioJefe de Servicio.

Stiglitz, J. E. (2003). La economía del sector público, volumen 24. Antoni Bosch Editor.

Subsecretaría de Desarrollo Regional y Administrativo (2005). Tipología: herramienta base pare el reconocimiento de la diversidad comunalmunicipal.

Transparency International Corruption Percepctions Index (2016).

Unesco (2014). Los medios de comunicación y el buen gobierno. 